\title{
Robert Cheize et Sylvie Chedemail, 1999, La dissertation en Géographie aux concours
}

Paris, Armand Colin, Collection Prépas-Géographie, 176 p.

Julien Mathieu

\section{OpenEdition}

\section{Journals}

Édition électronique

URL : http://journals.openedition.org/rge/4150

DOI : $10.4000 /$ rge.4150

ISSN : 2108-6478

Éditeur

Association des géographes de l'Est

Édition imprimée

Date de publication : 1 juin 2000

ISSN : 0035-3213

\section{Référence électronique}

Julien Mathieu, «Robert Cheize et Sylvie Chedemail, 1999, La dissertation en Géographie aux concours », Revue Géographique de l'Est [En ligne], vol. 40 / 3 | 2000, mis en ligne le 03 août 2013, consulté le 25 septembre 2020. URL : http://journals.openedition.org/rge/4150 ; DOl : https://doi.org/10.4000/rge. 4150

Ce document a été généré automatiquement le 25 septembre 2020

Tous droits réservés 


\title{
Robert Cheize et Sylvie Chedemail, 1999, La dissertation en Géographie aux
}

\section{concours}

Paris, Armand Colin, Collection Prépas-Géographie, 176 p.

\author{
Julien Mathieu
}

\section{RÉFÉRENCE}

Robert Cheize et Sylvie Chedemail, 1999, La dissertation en Géographie aux concours, Paris, Armand Colin, Collection Prépas-Géographie, 176 p.

1 Ce manuel se destine aux candidats à la préparation des écrits des concours de la fonction publique et de l'enseignement supérieur.

2 Les auteurs partent du constat, partagé par les jurys des différents concours, que trop souvent les candidats ignorent l'histoire même de leur discipline, pour justifier un court chapitre sur l'épistémologie de la Géographie depuis le début du XXe, qu'ils jugent nécessaire pour acquérir une réflexion géographique. Il est cependant regrettable que cette leçon n'aborde l'épistémologie de la Géographie que sous un angle réduit et surtout limité à l'Ecole française depuis sa naissance, alors que de nombreux concours, notamment l'Agrégation ou le CAPES comportent un éventail de questions qui touche à l'élaboration de cette discipline depuis l'Antiquité.

Plus loin, une méthode de dissertation rappelle les grands principes de cet exercice. On insiste sur un fait majeur : toujours lier arguments et exemples. Ces derniers, comme le signalent les auteurs, pourront être recherchés dans des revues de Géographie, dont ils ont dressé une courte liste des principaux titres et références mondiales, ce qui semble très utile. Pour illustrer cette démarche, le cours suivant permettra aux candidats de s'entraîner grâce à des annales de sujets de tous les concours depuis 1989 et jusque 1998. 
4 Une approche précieuse pour les étudiants peaufine les conseils méthodologiques précédemment décrits en s'employant à montrer les erreurs à éviter lors de la rédaction du devoir ou encore comment mettre en fiche un livre.

5 Le mérite de cet ouvrage est de démontrer le caractère incontournable de toute dissertation de Géographie: l'illustration. Les auteurs décrivent alors les principes fondamentaux de la cartographie : chorèmes, couleurs, légende, variations d'échelle... Ils insistent sur le fait qu'un croquis soigné, bien légendé et adéquat remplace un long paragraphe.

6 Enfin, pour chacun des concours visés un certain nombre de sujets est traité sous forme de plans détaillés.

7 Cet ouvrage clair et précis dans ses développements est non seulement réservé aux candidats des concours mais aussi à tout étudiant désireux d'acquérir méthodologie et connaissances épistémologiques nécessaires à la pratique de la Géographie.

\section{AUTEURS}

\section{JULIEN MATHIEU}

Université Nancy 2 